\title{
Risk management as a modern sustainable development of the enterprise management tool
}

\author{
$K . V$. Aikhel $^{1, *}$ \\ ${ }^{1}$ South Ural State University, Chelyabinsk, Russia
}

\begin{abstract}
Actively embedding in the international market processes, domestic industrial enterprises improve their management tools to create competitive structures. Spread one of the modern approaches to Business Engineering defines risk management as the starting point of building processes of the company. Adapting the method of analyzing hierarchies for quantitative risk assessment will increase the efficiency for the implementation of the new management approach, taking into account the existing time limits and the initial data, which in turn will ensure the stability of enterprises operations in the face of uncertainty. From the point of view of prospect of development, stability of the modern enterprises is also reflection of their competitiveness.
\end{abstract}

\section{Introduction}

Stability and sustainable development of enterprises are the signs of conduct of its proper functioning. Degeneration of the domestic industry after the recognition of disability centralized economy of the Soviet Union was focused on the creation of new organizational structures and operating principles that ensure survival in the marketplace [17, 19]. Therefore, the problem of introduction of modern management approaches to generate real business machines that can stably exist in an open international economy for the long term (Figure 1).

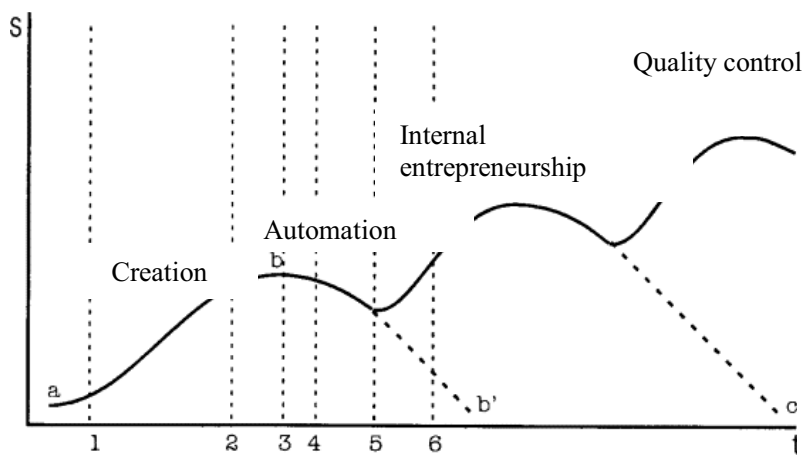

Fig. 1. Organizational Development Cycles.

The turbulence of the markets in the beginning of the XXI century, can undergo a huge number of bifurcations, has formed a new economic paradigm [20, 21]. In view of the fact that complex systems have the properties of high sensitivity with respect to fluctuations, the basis of a new approach to management has become a knowledge economy. The growing pace of globalization coexist with internal policies of the klienting modern enterprises, pulling technology and lean manufacturing philosophy system theory of constraints - the active implementation of the principles of controlling [6, 16]. Blend in with the modern quantitative management school, all these approaches are focused on providing much needed for sustainable development of modern industrial enterprises.

The utilitarian sense resistance characterizes the ability of an object to resist external influences. In practice, most of the economic stability of a company is analyzed only from the perspective of its financial situation [9]. Company Economic sustainability - a much more complex concept, defining the role and place as a subsystem in the system of higher order regional, federal and industry $[13,15]$.

Opportunities to maintain and enhance the economic sustainability of the company depends on how well its management are able to avoid the possible threats and to eliminate the harmful effects of the risk of external and internal environment, select the appropriate options for the management of actions under uncertainty $[1,18]$. The principle of sustainable imbalance is one of the main principles of the modern theory of self-organization synergy. Effective development of the organization in the innovation economy is determined by a combination of strategies, active use of domestic capacity for purposeful change of the external environment and continuous adaptation to it. The risk, as the competition is the driving force behind the sustained development, he - one of the objective moments to create and innovate.

The dynamics of the overall economic performance of the domestic industrial enterprises 2010-2014, due to differences in the post-crisis recovery. Given the structure of imbalances in the spheres of production, not much volatility in the overall pace of economic development, decreasing from $110 \%$ to $102 \%$, clearly

Corresponding author: aikhelkv@susu.ac.ru 
reflects the situation of recession [2]. Weak innovation activity, imbalance in the technical and technological characteristics, inertial development - digitized visual evidence of low competitiveness and unpreparedness of Russian companies to work in a crisis.

According to official statistics, in 2013 the financial sustainability of the country's industrial enterprises is low:

- slightly less than 5000 of unprofitable enterprises in the sector of manufacturing industries (about $30 \%$ of the total);

- the total debt of operating companies of manufacturing sector at 18 billion rubles;

- reduction of the current liquidity ratio from $146.1 \%$ to $131.2 \%$;

- a significant increase in negative ratio of its own working capital from $8.2 \%$ to $-35.1 \%[10,12]$.

A survey of three hundred Russian companies showed that only $29 \%$ of companies participating in the study have a functioning corporate risk management system. At the same time $90 \%$ of the companies of the real sector of the Russian economy do not have a system of financial motivation of managers to better risk management, and, in spite of the awareness of the need to introduce a risk-based approach, $80 \%$ of companies do not conduct regular training of personnel in the area of risk management [5].

Recovery of the domestic industry performance by means of the introduction of new management approaches is of particular relevance in a given time period. Adaptation and detail complex available tools of modern business engineering, despite the duration and intensity of fundamental organizational changes will be in the nature of health measures for a number of Russian enterprises.

\section{Theoretical framework and literature review}

Research problems of economic risk is actively implemented in many countries with developed market economies. In the 1960s, scientists in the United States, among which includes T. Mos, R. Mer B. Hedzhers, developed a comprehensive theory of the risk of a commercial organization. A significant contribution to this subject made by such well-known western writers like William Ting, W. Anderson, G. Magnusson, W. Arsur, C. Stone and OE in the Russian Federation in the sphere of problems of risk management began to be updated relatively recently, probably in the last 20-25 years. Russian researchers have turned their attention to the study of the problem in the post-transition period market economy. Among them, AP Algin, IT Balabanov, PG Hornbeam, JJ Kinev, GB Kleiner, L. Skamay, VD Shapiro et al. Summarizing and supplementing studies, practical implementation issues were actively engaged in the duma N., N. Kondratyev, A. Korezin, Yuri Kuznetsov, A. Petrov, A. Yudanov.

A series of existing standards for risk management of different levels of influence, such as FERMA: 2002, the COSO: 2004, ISO 31000: 2009 AS / NZS 4360: 2004, are quite similar algorithms for its implementation [4]. Based on the development of a common policy, taking into account the individual characteristics and goals of the enterprise, through the stages of identification and risk assessment, passing to make informed management decisions. A significant role for risk monitoring, analysis and optimization of management costs, providing cyclical and continuous monitoring.

Compliance with the development of the organization's management system on the basis of risk management to the mainstream internal openness and accessibility, is the need to create certain conditions and the possibility of involvement of employees in organization management. To ensure that all its employees are motivated for the development of new analytical and management tools and is actively involved in identifying risk factors for the development of his company's business. [11, 22]

Current in the real sector of the economy the concept of Business Intelligence (the BI), implies the existence of a clear pattern, clear enterprise team and allows you to connect the input of business resources to its final result for the interest period (Figure 2).

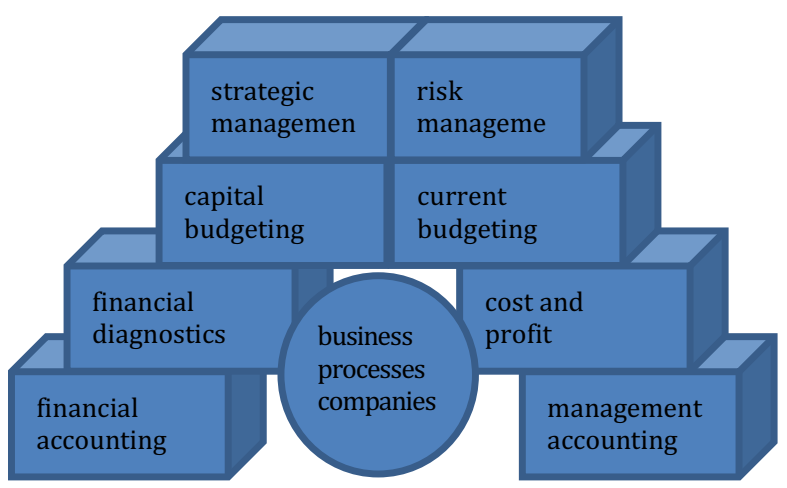

Fig. 2. The concept of Business Intelligence [8].

Popularized the practice of visualization purposes and the formation of a system of key performance indicators - Key Performance Indicator (KPI) - will be of the greatest value in the context of the application of risk-based approach, based on data from well-organized management accounting. In this case reached full integration of business processes, their continuity, preventive, efficiency, simplicity and accessibility, with a reference to the long-term dynamic growth, which in turn would lead to significant sustainability indicators of the national economy as a whole.

\section{Materials and methods}

A key technical challenge of implementation of risk management in practice, is the choice of tools to assess the significance of risk events on the possible consequences of their occurrence. The presence of highquality methods of assessment (risk rose, events, trees, method of analogies, expert characteristics) should be combined with appropriate quantitative. The use of the latter is accompanied by a number of difficulties associated with limited access to the original 
information. Due to poorly organized fixation and low reliability of statistical information, both internal and external to the domestic industrial enterprises, mathematical valuation methods (such as the backanalysis, extrapolation, probability theory tools) is not always possible to obtain reliable results. Accordingly, the importance of acquiring expert assessments and predictive models. If possible, use the most correct scripts let you receive the simulation model, game theory, stress-testing methodology. In the absence of sufficient quantity or diversity of the initial information the general trends of the risks can be estimated using expert opinions.

\section{A. Description of the methodology.}

One of affordable, relatively easy to implement and provide the opportunity for structuring of management, is the analytic hierarchy process - methodological basis for solving problems of selection of alternatives through their multi-criteria for rating. hierarchy analysis method created by T. Saaty American scientists at the end of the $\mathrm{XX}$ century and has grown now into a vast multidisciplinary branch of science that has rigorous mathematical and psychological studies and numerous applications.

The essence of the method is to decompose the problem into simpler component parts and further processing sequence face judgment, decision-making, for paired comparisons. The problem is structured and presented in a tree or hierarchical structure of the network, as a result of the relative degree of interaction of the elements in the hierarchy can be expressed. Computational aspects of the MAI associated with operations over back-symmetric matrices of paired comparisons (expert judgment). As a result of mathematical operations on each of the matrices can be calculated judgments priorities compared elements objects on the levels of the hierarchy and the degree of consistency of judgment.

In the hierarchy of elements are allocated in two types: elements- "parents" and elements- "descendants". The matrices of paired comparisons are being built for the elements-all "descendants," referring to the corresponding elements - "parent." Each cell of the matrix of pairwise comparisons really does not contain a single number (the result of a direct comparison) and a vector (including all indirect comparisons through comparison with other factors). Accounting for these additional comparisons can significantly improve the reliability of the results.

\section{B. Economic-mathematical model}

After placement scores within a matrix of pairwise comparisons, direct processing of data hierarchy implies a valuation of the estimates (Formula 1) and the calculation of the priorities of the vector (Formula 2):

$$
n_{i j}=\frac{a_{i j}}{\sum a_{i j}}
$$

where $n_{i j}$ - rationing scoring in each matrix of pairwise comparisons of the cell; $a_{i j}$ - Scoping pairwise comparison of elements of a certain level in the hierarchy; $\Sigma a_{i j}$ - aggregated numerical score within each column of the matrix.

$$
w=\frac{\sum n_{i j}}{k}
$$

where $w$ - the vector of priorities defined for each element of a certain level of the hierarchy; $\Sigma n_{i j}$ - the aggregate value of the normalized scores within each row of the matrix; $k$ - the number of elements of the hierarchy level, compared within this matrix [7].

As a result of the direct hierarchy data, obtained totals for each level of each element. Processing data hierarchy in reverse order starting from the 2 nd level of the hierarchy and implies taking into account the priorities of the vectors obtained at the higher levels. Calculations carried out by multiplying the corresponding vectors and matrices.

Hierarchy analysis method also involves checking the consistency of the resulting matrix. From linear algebra we know that positive definite back-symmetric matrix having a rank equal to 1 , the maximum eigenvalue equal to the dimension of the matrix, that is, n. When compared to the actual situation the calculated maximum eigenvalue $\lambda \max$ will differ from the corresponding own number for the ideal matrix. This difference characterizes the so-called mismatch real matrix. And, accordingly, characterizes the level of confidence in the results. The higher the contrast, the less confidence.

An important element of the settlement of the MAI is to define the so-called coherence index (SI):

$$
A I=(\lambda \max -n) /(n-1)
$$

He is the one who gives information about the degree of violation of the numerical (dramatically) and transitive (ordinal) consistency.

There is a need to pay a special attention to the iterative process of using AHP. If found to be insignificant experts any hierarchy of elements or, on the contrary, the need to include additional elements cognitive model, the adjustment can be performed with or models except the respective blocks.

\section{Conclusions}

Adaptation of Analytic Hierarchy Process in Risk Assessment, ultimately, allows to generate the rating, which determines the priorities of future management decisions. If necessary, the assessment can be carried out in two stages: the relative probability of occurrence of risk events and the possible amount of damage. The data obtained in this case can be constructed matrix of integrated assessment, including the permissible area of critical and catastrophic situations. Convenience method as is t)he availability of a quick update of the results of calculations, when the state of the individual factors of the external and internal environment. 
The ability to automate the analytic hierarchy process and its application opportunities not only for stations of the risk assessment, but also for the follow-management decisions, monitoring and prioritization, cause its key role in the implementation of risk management in the enterprise. Availability of relevant structured data source management accounting and statistics will enable to minimize the level of subjectivity in the assessment.

Multivariance risk management involves a combination of knowledge of standard and unique features of financial combinations, flexibility and originality of certain ways of acting in a particular economic situation. Availability of general theoretical guidelines and practical tools available, a reference to the personality development of the enterprises, professional understanding of trends and the current market situation, support real economic activity data management accounting - the basis of the successful implementation of risk-based approach in the context of the modern concept of Business Intelligence (BI).

The work was supported by Act 211 Government of the Russian Federation, contract № 02.A03.21.0011

\section{References}

1. M.A. Betilgiriev, Management of economic systems (2012). www.uecs.ru.

2. O.I. Izryadnova, Economy. Taxes. Right, 2, 69-80 (2015)

3. A.M. Iylshev, A.V. Karavayeva, Problems of modern economy, 4, (2007). http://www.meconomy.ru.

4. N.V. Kapustina, Methodology of management of development of the organization on the basis of risk management (Economics, St. Petersburg, 2015)

5. A.M. Maps, Risk management in the system to ensure the economic stability of the company (Moscow, 2014)

6. T.A. Khudyakova, of the International Congress on Interdisciplinary Behavior and Social Science, 292294 (2015)
7. T. Saaty, Decisions. Analytic Hierarchy Method, (Radio and Communications, Moscow, 1993)

8. V.P. Savchuk, Business Intellegenc: principles, technologies, training. www. delovoymir.biz.

9. S.G. Spirina, Russian economic magazine online, $\mathbf{1}$, 19 (2014)

10. Trends in the development of the industrial complex 2015: Report of the Ministry of Economic Development, the Department of sectors of the economy. www.economy.gov.ru.

11. T.A. Khudyakova, A.V. Shmidt, Proc. of The 26th International Business Information Management Association Conference, 1607-1611 (2015)

12. The Federal Service of State Statistics. www.gks.ru/bgd/regl/b14_48/Main.htm.

13. T.A. Khudyakova, A.V. Shmidt, Proc. of The 26th International Business Information Management Association Conference 1617-1625 (2015)

14. M.G. Efimova, Proc. Breakthrough economic reforms in the conditions of risk and uncertainty, 53-55 (2015)

15. I.A. Baev, A.V. Shmidt, Bulletin of Ural Federal University, Series: Economy and Management, 3, 50-63 (2012)

16. N.Y. Varkova, Production management (Publishing center SUSU, Chelyabinsk, 2009)

17. A.V. Shmidt, T.A. Khudyakova, Proc. of The 27th International Business Information Management Association Conference (2016)

18. A.A. Nikolaenko, Proc. Science SUSU, 1517-1525 (2015)

19. E.S. Pishchulina, Service: economics, technics, education (2015)

20. V.V. Zhuravlyov, Proc. International scientificpractical conference, 37-39 (2015)

21. A.V. Shmidt, T.A. Khudyakova, Proc. of The 27th International Business Information Management Association Conference (2016) 